\title{
BACIA HIDROGRÁFICA DO RIO DA VÁRZEA - RS: O PAPEL DO ÓRGÃO GESTOR
}

\author{
P. D. C. KEMERICH ${ }^{1 *}$, L. G. RITTER ${ }^{2}$, V. F. DULAC ${ }^{2}$ e R. C. CRUZ ${ }^{1}$ \\ ${ }^{1}$ Universidade Federal do Pampa \\ ${ }^{2}$ Universidade Federal de Santa Maria \\ eng.kemerich@yahoo.com.br ${ }^{*}$
}

Artigo submetido em maio/2013 e aceito em abril/2015

DOI: $10.15628 /$ holos.2015.1417

\section{RESUMO}

Os comitês de gerenciamento de bacias hidrográficas são colegiados instituídos oficialmente pelo Governo do Estado que representam a instância básica de participação da sociedade no Sistema Estadual de Recursos Hídricos, devendo promover a gestão participativa e social, sendo que os mesmos devem ser compostos por vários segmentos da sociedade, dentre eles: setores usuários da água, sociedade civil organizada e órgãos públicos envolvidos na questão dos recursos hídricos. Cabe aos comitês acompanhar a implementação dos instrumentos de gestão dos recursos hídricos e amenizar conflitos entre os diferentes atores sociais envolvidos, a fim de que as necessidades sejam atendidas, mas sempre levando em consideração a conservação das águas. Deste modo o objetivo do presente trabalho é avaliar a evolução das ações do Comitê de Bacia do Rio da Várzea e seus impactos na implementação do Sistema Estadual de Recursos Hídricos na respectiva bacia. Para efetivar tais propósitos, tanto as deliberações como os projetos aprovados contidos nas atas do comitê foram classificados pela pesquisa, segundo a natureza do assunto. Observou-se que o Comitê apresenta problemas relacionados principalmente à falta de participação dos membros e escassez de recursos financeiros. A elaboração do Plano de Bacia, apesar de ainda não apresentar todas as fases concluídas, corrobora com a questão do planejamento da conservação, em quantidade e qualidade, da água na bacia hidrográfica, e tem por finalidade fundamentar e orientar a implementação da Política Estadual de Recursos Hídricos, assegurando as metas e os usos neles previstos, na área da bacia.

PALAVRAS-CHAVE: Recursos hídricos, Conservação, Comitê de Bacia.

\section{RIVER BASIN OF VÁRZEA - RS: THE ROLE OF THE BOARD MANAGER}

\begin{abstract}
Committees watershed management boards are officially instituted by the State Government to represent the basic instance of participation of society in the State System of Water Resources should promote participatory management and social, and they should be composed of several segments of society, including: water user sectors, civil society organizations and government agencies involved in the issue of water resources. It is up to the committees to monitor the implementation of the instruments of management of water resources and mitigate conflicts between different social actors involved, in order that the needs are met, but always taking into account the conservation of water. Thus the aim of this work is to evaluate the evolution of the shares of the Committee
\end{abstract}

of the Meadow River Basin and its impact on the implementation of the State System of Water Resources in its basin. To accomplish these purposes, both the deliberations and approved projects contained in the minutes of the committee were classified by the survey, according to the nature of the subject. It was noted that the Committee presents problems mainly related to the lack of participation of members and lack of financial resources. The development of the Basin Plan, although not submit all completed stages, corroborates the issue of conservation planning, quantity and quality of water in the basin, and aims to support and guide the implementation of the State Policy Water Resources, ensuring the goals and purposes therein and in the basin

KEYWORDS: Water resources, Conservation, River Basin Committee. 


\section{INTRODUÇÃO}

Os comitês de gerenciamento de bacias hidrográficas são colegiados instituídos oficialmente pelo Governo do Estado que representam a instância básica de participação da sociedade no Sistema Estadual de Recursos Hídricos (SEMA, 2008).

Os comitês de bacias hidrográficas configuram-se como instituições relativamente recentes no Brasil, criadas nas duas últimas décadas do século $X X$, em um contexto de descentralização da gestão implementado pelo Estado, notadamente a partir da Constituição Federal de 1988 - CF/1988, onde a competência de alguns aspectos da gestão de recursos hídricos, bem como da gestão ambiental, está relacionada aos três entes federados, dispostas no art 23. da CF .

Cada Comitê conta com uma diretoria composta de um presidente e um vice-presidente. Além disso, atendendo ao disposto na Lei Estadual no 10.350/94, a qual institui o Sistema Estadual de Recursos Hídricos do Rio Grande do Sul - SERH-RS e regulamenta o funcionamento dos Comitês, estes elaboram seu respectivo regimento interno. Normalmente, define-se a partir do Regimento Interno que o organismo conte com uma secretaria executiva e com uma comissão permanente de assessoramento. O secretário executivo é escolhido pela diretoria com o aval do Comitê. A comissão permanente de assessoramento, cujo número de integrantes e forma de escolha varia conforme o Comitê tem a função de secundar a diretoria na preparação e na execução das atividades do Comitê (CÁNEPA E GRASSI, 2001).

A legislação de recursos hídricos concede aos comitês atribuições poder para deliberarem sobre o processo de planejamento de suas respectivas bacias, bem como opinarem sobre o Plano Estadual de Recursos Hídricos, entre outras atribuições (art. 19, Lei 10.350/1994) (SEMA, 2008).

Os comitês de bacia hidrográfica são regulamentados pela Legislação Federal de Recursos Hídricos Lei no 9433/97, e segundo a qual devem promover a gestão participativa e social, sendo que os mesmos devem ser compostos por vários segmentos da sociedade, entre eles: setor dos usuários da água, sociedade civil organizada e órgãos públicos envolvidos na questão dos recursos hídricos. Cabe aos comitês amenizar conflitos entre os diferentes atores sociais envolvidos, a fim de que as necessidades sejam atendidas, mas sempre levando em consideração a conservação das águas (MEIER, 2011).

Funcionando como fórum integrador de políticas, o comitê tem o potencial de articular a política de recursos hídricos com a política ambiental, socioeconômica e de uso do solo, entre outras, possibilitando gerenciar de forma integrada e sustentável a utilização e conservação dos recursos naturais da bacia hidrográfica (MASCARENHAS, 2006).

Ao atribuir aos comitês o gerenciamento dos recursos hídricos, centralizado no mesmo, torna-se possível um novo mecanismo de cooperação multilateral entre a esfera federal e as demais, na solução de problemas regionais, sobretudo nas regiões conturbadas (NASCIMENTO E VILLAÇA, 2008).

No entanto, os comitês tem enfrentado dificuldades na sua implementação, como é relatado por Costa (2002) que, com base em sua experiência, afirma que os problemas dos 
comitês começam com a ausência de pautas concretas, aliadas a burocracia do estado diminuindo assim o número de participantes das reuniões.

Como os comitês estão centrados na participação social, esta torna-se outra dificuldade dos comitês, pois para que ela ocorra verdadeiramente necessita de representação e representatividade de seus membros. Segundo Meier (2011), a falta de representatividade dos comitês junto à sociedade pode estar ancorada na falta de representatividade da sociedade junto aos comitês.

O processo de financiamento dos comitês é outro segmento que dificulta a sua atuação, e este aspecto só apresentará mudanças à medida que se instituir a cobrança do uso da água (PAIM, 2010).

Analisar as discussões, deliberações e projetos aprovados pelo comitê, permite identificar todas as suas decisões mais importantes, referentes à aplicação e uso de suas atribuições, bem como quanto a recursos a serem aplicados na Bacia.

Segundo Cury (2005), através dos documentos oficiais do Comitê, como as atas das plenárias, é possível analisar os diversos segmentos representados no Comitê e a atuação de suas forças, os participantes mais ativos, os temas debatidos e o destino dado a eles diante do fato de terem sido discutidos num fórum regional.

Dessa maneira, o presente trabalho tem por objetivo avaliar a evolução das ações do Comitê de Bacia do Rio da Várzea e seus impactos na implementação do Sistema Estadual de Recursos Hídricos na respectiva bacia.

\section{METODOLOGIA}

\subsection{Localização e caracterização da área de estudo}

A Bacia Hidrográfica da Várzea situa-se ao norte do Estado do Rio Grande do Sul, entre as coordenadas geográficas $27^{\circ} 00^{\prime}$ a $28^{\circ} 20^{\prime}$ de latitude Sul e $52^{\circ} 30^{\prime}$ a $53^{\circ} 50^{\prime}$ de longitude Oeste. Abrange a Província Geomorfológica Planalto Meridional. Esta bacia possui área de $9.463,46 \mathrm{Km}^{2}$, abrangendo 55 municípios, conforme a Figura 1, com população estimada em 323.924 habitantes, sendo o seu comitê criado pelo Decreto no 43.488, de 08 de dezembro de 2004 .

O comitê é integrante do Sistema Estadual de Recursos Hídricos, previsto na Lei Estadual no 10.350/94, sendo mantido por regimento próprio elaborado em 2006 e homologado pela Resolução no 41/07 do CRH-RS e demais disposições legais. Sua sede fica localizada juntamente com o Conselho Regional de Desenvolvimento do Médio Alto Uruguai (CODEMAU), em Frederico Westphalen, Rio Grande do Sul (CBHV, 2010).

O CBHV constitui-se de 40 representantes titulares: dezesseis entidades representam respectivamente o grupo dos Usuários da água (40\%), dezesseis da População (40\%) e oito do Poder Público (20\%).

A seguir apresentam-se as categorias em que se subdividem os grupos Usuários e População, seguido do número de vagas referente a cada uma (DRH/SEMA, 2012): 
Grupo Usuários: Abastecimento público (2), esgotamento sanitário e resíduos sólidos (2), drenagem (2), geração de energia (1), produção rural (3), indústria (3), mineração (1), lazer e turismo (1), além da pesca (1).

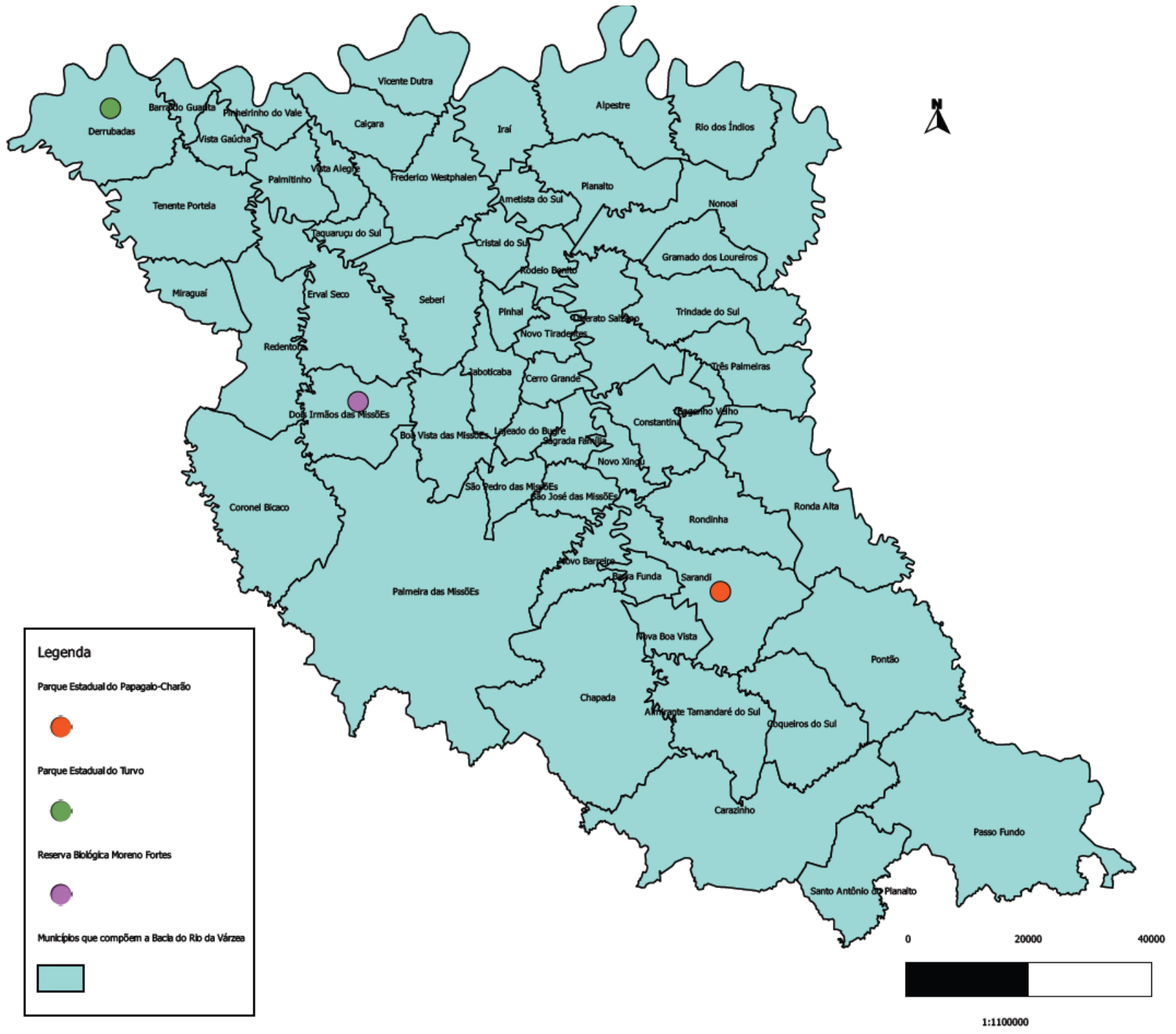

Figura 1: Municípios que compõem a Bacia Hidrográfica do Rio da Várzea e Unidades de Conservação na Bacia Fonte: Elaborada pelos autores

Grupo População: Legislativos estadual e municipal (3), associações comunitárias (2), clubes de serviços comunitários (1), instituições de ensino, pesquisa e extensão (3), organizações ambientalistas (2), associações de profissionais (2), organizações sindicais (2) e comunicação (1).

Grupo Poder Público: Não foram observadas discriminações em categorias no regimento e na referida Resolução.

A bacia tem dimensões de aproximadamente $140 \mathrm{~km}$ no sentido Norte-Sul. No sentido Leste-Oeste a bacia tem dimensão aproximada de $70 \mathrm{~km}$ na porção central da bacia, diminuindo no extremo Sul para aproximadamente $40 \mathrm{~km}$, com fator de forma igual a 0,4, caracterizando assim, uma bacia de forma alongada. Possui uma vazão média anual de $276,51 \mathrm{~m} 3 / \mathrm{s}$, sendo os 
principais cursos de água os arroios Sarandi, Goizinho e os rios da Várzea, Porã, Barraca, do Mel, Guarita e Ogaratim (ECOPLAN, 2007).

Os principais usos da água na bacia se destinam a irrigação, a dessedentação animal e ao abastecimento humano. As atividades econômicas são predominantemente agrícolas, com destaque para o cultivo de soja, trigo e milho, bem como avicultura e suinocultura. Destaca-se, ainda, o potencial hidrelétrico desta bacia e as atividades de mineração (extração de pedras preciosas e semi-preciosas, como ágata, ametista, etc.) (SEMA, 2010).

Atualmente, a bacia conta com 12 Pequenas Centrais Hidrelétricas (PCHs) em operação, licenciadas pelo Estado do Rio Grande do Sul, as quais contam com até $30 \mathrm{MW}$ de potência, além de mais $10 \mathrm{PCHs}$ em processo de licenciamento.

Tanto em termos absolutos (t/ano) como específicos (t/ano/ $\mathrm{km}^{2}$ ), a bacia do rio da Várzea é uma das maiores produtoras de dejetos de suínos do Rio Grande do Sul merecendo especial atenção com relação aos aspectos relacionados à poluição hídrica de origem animal, pois a bacia apresenta uma alta taxa, de cerca de 50 suínos por cada quilômetro quadrado (ECOPLAN, 2007).

Na Bacia do Rio da Várzea existem três Unidades de Conservação: duas unidades sob administração estadual e uma sob administração do município de Dois Irmãos das Missões (conforme Tabela 1).

Tabela 1: Unidades de Conservação na Bacia Hidrográfica do Rio da Várzea

\begin{tabular}{l|l|l|l|l}
\hline Unidade de Conservação & Classificação no SNUC & Localização & Área (ha) & Administração \\
\hline $\begin{array}{l}\text { Parque Estadual do Papagaio- } \\
\text { Charão }\end{array}$ & Proteção Integral & Rondinha, Sarandi & $1.000,00$ & Estadual \\
$\begin{array}{l}\text { Parque Estadual do Turvo } \\
\text { Reserva Biológica Moreno Fortes }\end{array}$ & Proteção Integral & $\begin{array}{l}\text { Derrubadas, } \\
\text { Esperança do Sul } \\
\text { Dois Irmãos das } \\
\text { Missões }\end{array}$ & $\begin{array}{l}17.491,40 \\
\text { Estadual }\end{array}$ & Municipal \\
\hline
\end{tabular}

Fonte: SEMA, 2008

\subsection{Metodologia de pesquisa e avaliação}

As ações do comitê, as quais foram objeto da avaliação, foram selecionadas a partir da leitura e sistematização das Atas de Reuniões Plenárias e as discussões, deliberações e projetos aprovados contidos nas atas, caracterizando assim fontes de dados primários. As atas avaliadas correspondem ao período de 26 de fevereiro de 2008 a 27 de maio de 2011, totalizando 14 atas, as quais foram obtidas junto à presidência do respectivo Comitê de Bacia, sendo a periodicidade atual das reuniões definida na Ata 01/2010, devendo as mesmas ocorrer a cada 45 dias.

A fim de compreender as ações priorizadas pelo comitê, estas foram classificadas em deliberações e projetos, de acordo com o trabalho de Cury (2005) e adaptado por Dulac et. al. (2012).

\footnotetext{
${ }^{1}$ Sistema Nacional de Unidades de Conservação

${ }^{2}$ Antigo Parque Estadual de Rondinha
} 
Entretanto, dado as diferenças entre as deliberações e projetos, algumas considerações são fundamentais no sentido de delimitar melhor o universo a ser avaliado. As deliberações normalmente são assuntos encaminhados e votados de forma paritária pelo comitê. Alvim e Ronca (2004) afirmam que em virtude do comitê ter uma natureza deliberativa e não executiva, em geral, sua atuação limita-se a recomendações referentes a Planos; Estudos; Legislações, entre outros, que dependem muitas vezes da ação efetiva do Estado, da União ou dos municípios, para sua execução.

Já os projetos aprovados no âmbito do comitê, são encaminhados para análise no Conselho de Recursos Hídricos do Estado do Rio Grande do Sul - CRH-RS, ou demandados pelo Estado e/ou União e tem sua implementação discutida no âmbito do comitê. Os projetos recebem recursos financeiros, principalmente do Fundo de Recursos Hídricos do Rio Grande do Sul - FRH-RS, para sua implementação, e podem ser considerados como uma das ações mais efetivas dessas instâncias, pois os projetos ali aprovados poderão auxiliar na manutenção e na preservação dos recursos hídricos aliada ao desenvolvimento.

Nas tabelas a seguir, apresentamos a classificação utilizada para as deliberações, conforme Tabela 2, e projetos, de acordo com a Tabela 3, baseada em Cury (2005), a qual foi adaptada por Dulac et al.(2012) e modificada neste artigo. A Tabela 2 apresenta as deliberações e os respectivos aspectos avaliados.

Tabela 2: Classificação das deliberações e discussões

\begin{tabular}{l|l}
\hline Deliberação & Aspecto Avaliado \\
\hline Administrativo & Auto-regulamentação administrativa do comitê \\
Normativo & Regulamentação regional de políticas de recursos hídricos \\
Financeiro & Critérios para a aplicação de recursos \\
Planos/Estudo e projetos & $\begin{array}{l}\text { Estudo e confecção de Planos e Projetos para as bacias } \\
\text { Eventos }\end{array}$ \\
& $\begin{array}{l}\text { Realização, apoio e participação em eventos de gestão } \\
\text { ambiental e de recursos hídricos na bacia }\end{array}$ \\
\hline
\end{tabular}

A classificação dos projetos e os aspectos avaliados estão discriminados na Tabela 3.

Tabela 3: Classificação dos projetos

\begin{tabular}{l|l}
\hline Projeto & Aspecto Avaliado \\
\hline Planos/Estudos e Projetos & Aprovação da elaboração de Planos e Projetos para as bacias \\
Obras & Aprovação de medidas estruturais na bacia \\
Ações Complementares & Relacionam-se a implementação de sistemas de gestão \\
Educação Ambiental & Realização de ações de educação ambiental nas bacias \\
\hline
\end{tabular}

Esta classificação foi modificada de Cury (2005) e Dulac et al. (2012), em função de características especificas do comitê. Para que se possa detectar a dinâmica do comitê em relação a estas categorias foi necessário considerar como deliberação os assuntos discutidos mesmo sem aprovação e/ou encaminhamento, uma vez que o Comitê do rio da Várzea apresentaria um baixo percentual de deliberações, se utilizássemos o mesmo conceito de deliberação dos supracitados estudos, o que inviabilizaria a análise aqui proposta. 


\section{RESULTADOS E DISCUSSÕES}

3.1 Avaliação das deliberações aprovadas em Atas do Comitê do Rio da Várzea

No período avaliado foram realizadas 14 atas de reuniões plenárias e aprovadas 37 deliberações pelo comitê, o que representa $100 \%$ das deliberações contidas nas atas encontradas, as quais foram avaliadas por assunto, conforme está discriminado na Figura 2.

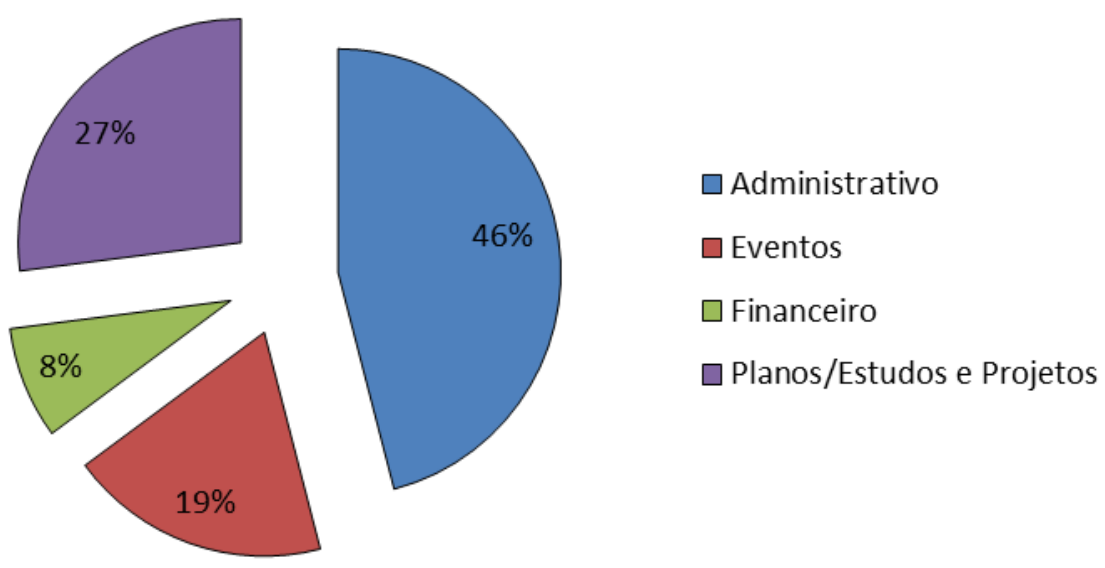

Figura 2: Deliberações aprovadas por assunto

No ano de 2008 o comitê apresentou o maior número de deliberações, totalizando 18, conforme é evidenciado na Figura 3, demonstrando uma intensa atuação em sua fase inicial, sendo que após esse período, houve uma diminuição no total de deliberações em relação ao ano de 2008.

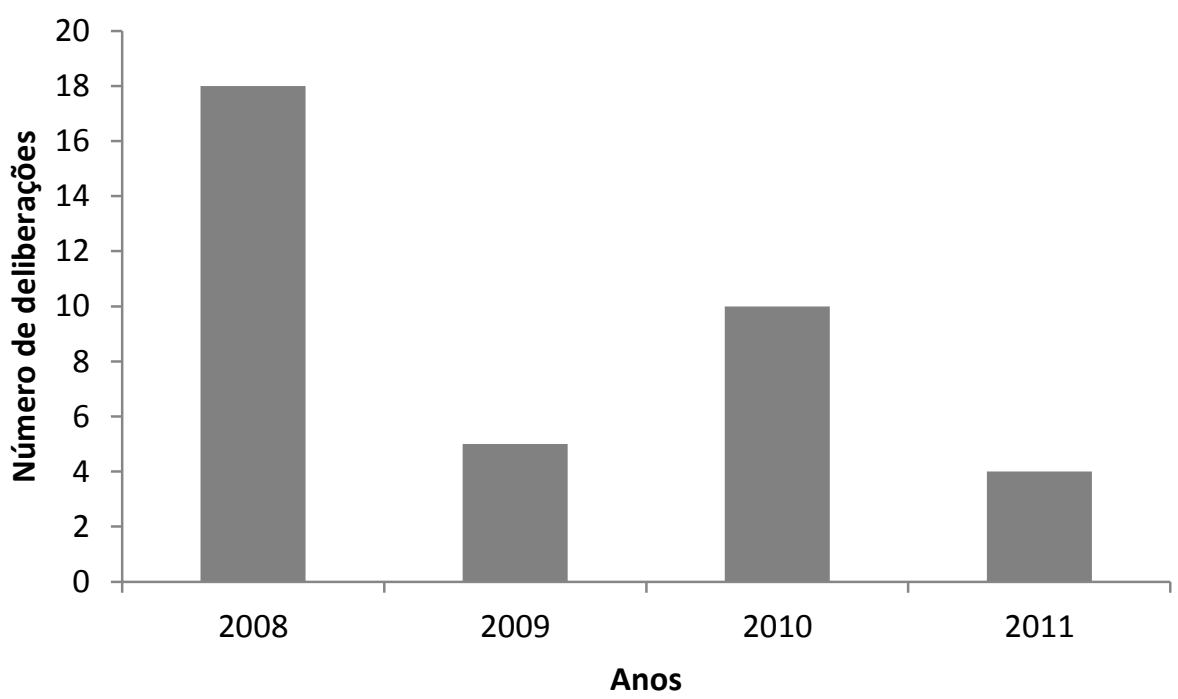

Figura 3: Deliberações aprovadas ao ano 
Em virtude do período de tempo analisado, torna-se difícil fazer associações entre as variações no número de deliberações ao ano e os períodos de início, final e entremeios de mandatos municipais e estaduais. É possível afirmar que o aumento no total de deliberações ao ano pode estar relacionado a períodos de início de mandatos municipais e estaduais.

Cury (2005), em seu estudo referente ao Comitê do Alto Paranapanema, localizado no Estado de São Paulo, verificou que ocorre uma diminuição da quantidade de deliberações em anos de início e final de mandatos municipais. Neste comitê ocorre efetiva participação dos órgãos públicos municipais, sendo a referida diminuição no número de deliberações explicada pelo fato de que é durante os mandatos municipais que são definidas questões sobre a distribuição de recursos financeiros do Estado para as prefeituras efetuarem ações da Política de Recursos Hídricos. Além disso, há o tempo despendido para indicação e adaptação de um novo representante municipal, quando ocorre uma mudança de representação da prefeitura.

Ao analisar o total de deliberações, observa-se a preponderância das deliberações de caráter administrativo, as quais correspondem a 17 deliberações, representando $46 \%$ do total. A elevada quantidade de deliberações de caráter administrativo evidencia que após o desmembramento do Comitê de Bacia Hidrográfica do Rio da Várzea do Comitê de Bacia Hidrográfica do Rio Passo Fundo, houve intenso período de reestruturação interna do comitê.

Dulac et al. (2012) observaram que através de uma melhor organização administrativa potencial, demonstrada através do alto índice de deliberações de caráter administrativo, o Comitê de Gerenciamento da Bacia Hidrográfica do Rio Santa Maria, passou a aprovar projetos mais específicos de controle e monitoramento da situação das águas da bacia (projetos aprovados no item "Ações Complementares"). No caso do comitê do Rio da Várzea, o aumento nas deliberações de caráter administrativo acarretou no aumento das deliberações relacionadas a Planos/Estudos e Projetos.

As deliberações relacionadas a Planos/Estudos e Projetos apresentam 10 deliberações, representando $27 \%$ do total. A partir da estruturação interna do comitê verificou-se um maior envolvimento com as questões referentes à situação ambiental da bacia hidrográfica, o que pode ter resultado no aumento do número de deliberações referentes a estudos na mesma. Dentre as deliberações aprovadas neste item cabe destacar as indicações decorrentes do projeto das barragens que serão construídas pela PEC Energia no Rio da Várzea entre os municípios de Frederico Westphalen, Ametista do Sul e Irai para as Pequenas Centrais Hidrelétricas (PCHs) Várzea do Sul e Duas Pontes. Por outro lado, há o indicativo por parte da Secretaria Estadual do Meio Ambiente (SEMA) da sua intenção de tornar o Rio da Várzea livre de barragens.

Ressalta-se a contradição evidenciada nas referidas indicações: de um lado a intenção de órgãos ambientais de lutar pela preservação, e de outro as empresas em busca do desenvolvimento - caracterizando um conflito político no que se refere à gestão de recursos hídricos na Bacia.

Em relação ao item Eventos, este apresenta 7 deliberações, representando 19\% do total, as quais correspondem principalmente a realização de palestras, cursos e eventos de capacitação. O comitê demonstra-se atuante quanto ao aprimoramento do conhecimento em recursos hídricos de seus membros, promovendo frequentes cursos de capacitação. 
O Estado do Rio Grande do Sul apresenta uma expressiva participação da população na composição dos comitês de bacia, estando esta bem representada, sendo que a maioria dos membros do comitê reside em municípios incluídos nas respectivas bacias, o que assegura um melhor relacionamento entre o comitê e a população local. O Comitê do Rio da Várzea possui uma grande área de abrangência, identificando-se assim dificuldades na participação dos membros nas reuniões, em função da distância, as quais ocorrem no município de Frederico Westphalen - RS. Esse resultado corrobora com os estudos de Haase (2005), feitos nas Bacias do RS, nos quais a autora afirma que quanto maior a bacia, maiores as distâncias entre os municípios, dificultando o acesso à participação.

Já as deliberações de caráter financeiro representam $8 \%$ do total, correspondendo a 3 deliberações, estando estas relacionadas principalmente a questões referentes ao orçamento interno do comitê. No ano de 2011, os recursos destinados pela SEMA para a manutenção do Comitê via convênio com o CODEMAU, foram devolvidos aos cofres públicos, pelo fato da diretoria do CODEMAU, entender que poucas atividades foram desenvolvidas pelo Comitê no decorrer do ano anterior, para justificar os gastos. No entanto, consta em ata que a secretária do comitê, na época, estava trabalhando para o Comitê sem que houvesse repasse de recursos a mais de dois anos.

Assim, verifica-se que a dificuldade do CBHV em se adaptar à burocracia do Estado repassada à gestão financeira dos Comitês.

Outro aspecto que pode ser observado é uma possível baixa concretização de atividades em recursos hídricos desenvolvidas pelo Comitê de acordo com as discriminações da SEMA. Assim, observa-se que a utilização destes recursos está condicionada ao desempenho do comitê.

No período avaliado, não foi verificada a aprovação de nenhuma deliberação de caráter normativo, demonstrando que o comitê não apresenta avanços em relação a regulamentação regional das políticas de recursos hídricos.

3.2 Avaliação dos projetos aprovados em Atas do Comitê de Bacia Hidrográfica do Rio da Várzea

Ao longo do período analisado foram aprovados 10 projetos, com destaque para os projetos relacionados a ações de educação ambiental, conforme é evidenciado na Figura 4.
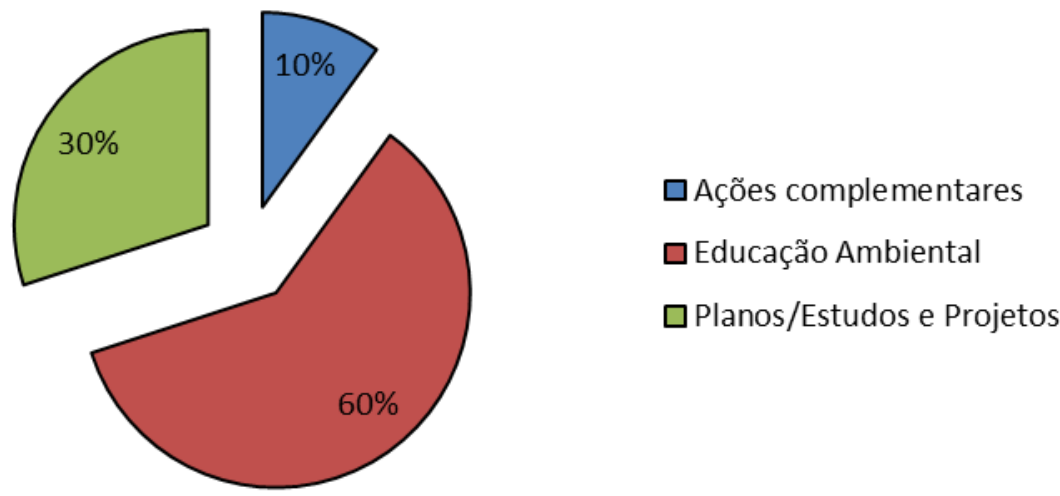

Figura 4: Natureza dos projetos aprovados 
Quanto à aprovação de projetos, esta foi verificada somente em dois anos- 2008 e 2010, conforme a Figura 5.

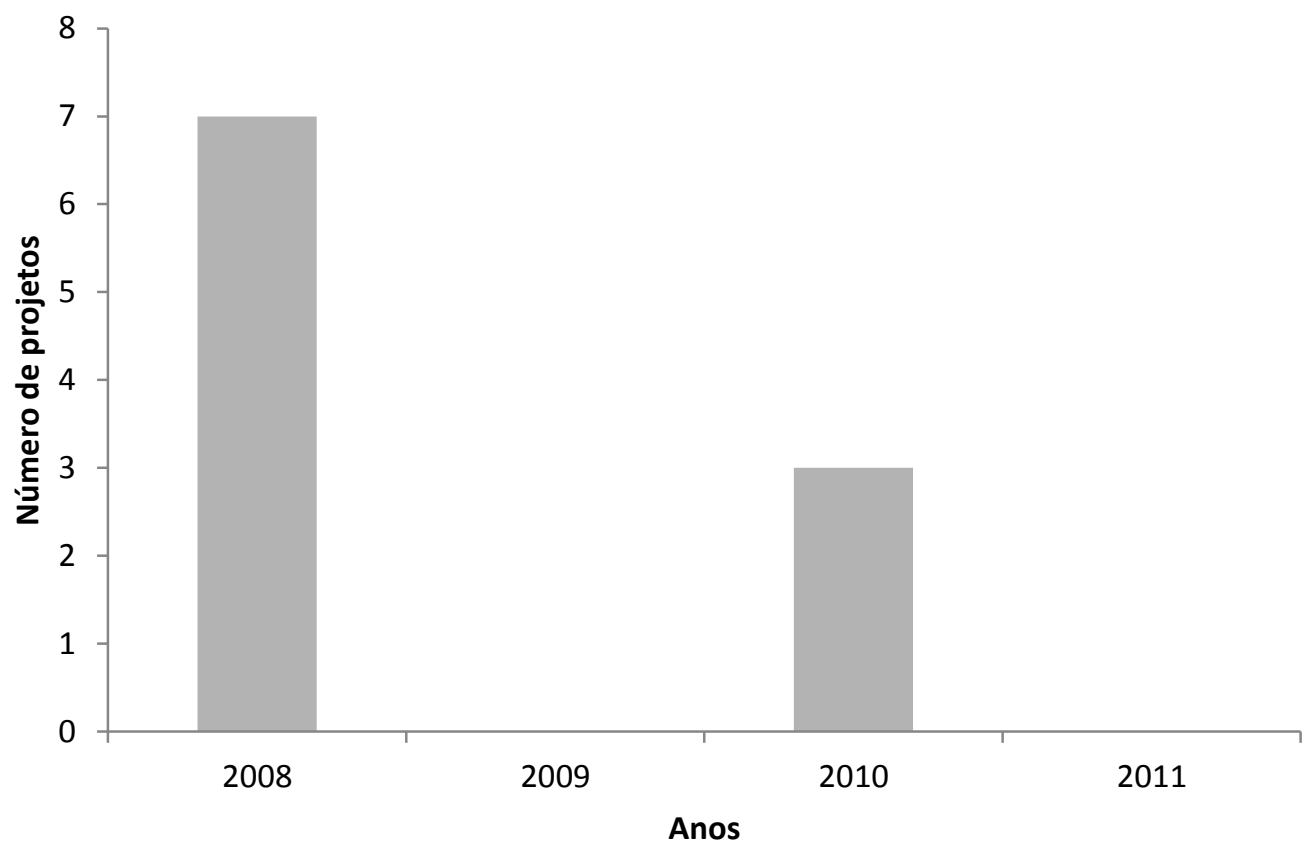

Figura 5: Número de projetos aprovados ao ano

Os projetos relacionados a ações de educação ambiental correspondem a maior parcela aprovada, sendo estes 6 projetos, o que representa $60 \%$ do total. Ocorre uma distribuição semelhante nos anos de 2008 e 2010, o que demonstra a atuação constante do comitê neste assunto.

Neste sentido, a educação ambiental é um instrumento valioso para a gestão de recursos hídricos, tanto na manutenção de sua qualidade e preservação de sua quantidade, quanto na sensibilização de suas formas de uso pela sociedade (ETGES, 2000).

$\mathrm{Na}$ categoria referente a planos/estudos e projetos, foram 3 aprovados, o que corresponde a $30 \%$ do total. O projeto de maior relevância refere-se à avaliação do Termo de Referência para a elaboração do Plano de Bacia, que ocorreu no ano de 2008 e, após aprovação, o mesmo foi imediatamente encaminhado ao Departamento de Recursos Hídricos (DRH) para homologação, sendo que a elaboração do Plano de Bacia encontra-se em andamento.

Cabe ressaltar que o Plano de Bacia consiste no instrumento de planejamento (art 25 da Lei Estadual no10.350/1994) o qual tem por finalidade fundamentar e orientar a implementação da Política Estadual de Recursos Hídricos, compatibilizando os aspectos quantitativos e qualitativos do uso das águas, de modo a assegurar as metas e os usos neles previstos, na área da bacia.

Já quanto aos projetos aprovados referentes a ações complementares, somente um foi aprovado, tratando da compensação ambiental devida aos municípios impactados diretamente 
pelo lago do empreendimento da usina Foz de Chapecó, onde o comitê fez uso da Câmara Técnica do Rio Uruguai, para que fosse encaminhado com veemência a consulta efetuada à Assessoria Jurídica da SEMA a respeito dessa questão.

No período avaliado, não foi verificada a aprovação de nenhum projeto referente a obras, demonstrando a não participação do comitê na aprovação de medidas estruturais na bacia hidrográfica.

Faz-se necessária a implantação dos Instrumentos de Gestão de Recursos Hídricos na Bacia através de medidas como a Outorga, a cobrança pelo uso da água, o enquadramento dos corpos d'água e a continuidade na elaboração do Plano de Bacia, para que assim o comitê possa acompanhar a implantação dos instrumentos de gestão, o que é sua função, enquanto a função executiva do Sistema de Recursos Hídricos compete tanto ao órgão gestor Estadual - o DRH, quanto às Agências de Região Hidrográfica (ARH). No entanto as últimas não foram implantadas no Estado do RS.

\section{CONSIDERAÇÕES FINAIS}

Conclui-se que no período analisado as deliberações de caráter administrativo e as referentes a planos/estudos e projetos apresentaram preponderância dentre as outras categorias. Já em relação aos projetos, apresentaram preponderância aqueles referentes à categoria Educação Ambiental (60\%) e Planos/Estudos e Projetos (30\%), correspondendo à categoria Ações Complementares apenas $10 \%$ do total de projetos. Evidencia-se assim a preocupação do comitê com a estruturação interna do mesmo e com as questões referentes à bacia hidrográfica, sendo estes resultados de uma auto-estruturação maior e do autoconhecimento da bacia obtido dos projetos aprovados.

A elaboração do Plano de Bacia, apesar de ainda não apresentar todas as fases concluídas, busca através da realização de um diagnóstico da situação dos recursos hídricos, corroborar com a questão do planejamento da conservação dos recursos hídricos. Espera-se que, com o Plano se possa aprimorar o sistema de outorgas bem como tornar mais favorável a situação para implantação da cobrança pelo uso da água uma vez que a destinação dos recursos da cobrança (para investimentos em medidas estruturais ou não estruturais para beneficiar os múltiplos usos da água) estão vinculadas às prioridades definidas no Plano de bacia.

\section{REFERÊNCIAS BIBLIOGRÁFICAS}

1. CÁNEPA, M. E.; GRASSI, L. A. T. Os Comitês da Bacia no Rio Grande do Sul - uma experiência histórica. Ciência e Ambiente, N. 21. Universidade de Santa Maria, Santa Maria, 2001.

2. CBHV - Comitê de Gerenciamento da Bacia Hidrográfica do Rio da Várzea. Comitê Várzea. 2010. Disponível em: <http://comiteriodavarzea.blogspot.com.br/>. Acesso em: 13 ago. 2013.

3. COSTA, F. J. L. Debates. In: MONTICELI, João Jerônimo (Coord.). Organismos de Bacias Hidrográficas. Rio de Janeiro: Semads, p. 17-28, 2002.

4. CURY, J. F. A Gestão Integrada de Bacias Hidrográficas: A Abertura de uma oportunidade 
para o Desenvolvimento Sustentável do Alto Paranapanema (1994-2004). Tese de Doutorado em Estruturas Ambientais Urbanas, Faculdade de Arquitetura e Urbanismo, Universidade de São Paulo, São Paulo, 350p, 2005.

5. DULAC, V. F.; BAGGIOTTO, C.; CRUZ, J. C.; CONSENSA, C. B. Classificação das deliberações e projetos aprovados pelo Comitê de Bacia Hidrográfica do Rio Santa Maria. 3 Congresso Internacional de Tecnologias para o Meio Ambiente, Bento Gonçalves, 2012.

6. ECOPLAN ENGENHARIA. Ltda. Plano Estadual de Recursos Hídricos do Rio Grande do Sul. Relatório Síntese da Fase A - Diagnóstico e Prognóstico Hídrico das Bacias Hidrográficas do Rio Grande do Sul. Porto Alegre, 146p, 2007.

7. ETGES, V. E. Apresentação. In: NOAL, E.O.; REIGOTA, M.; BARCELOS, V.H. (ORG) Tendências da educação ambiental brasileira. Santa Cruz do Sul: EDUNISC, p. 9, 2000.

8. GRANDES e Pequenas Centrais Hidrelétricas na Bacia do Rio Uruguai: Guia para ONGS e Movimentos Sociais. Coordenação e revisão Anelise Hüffner e Bruna Cristina Engel. ed. atual. Porto Alegre: Amigos da Terra - NatBrasil, 2011.

9. HAASE, J. O Encontro Estado e Sociedade na Política Gaúcha das Águas. 315p. Tese de Doutorado em Ecologia, Universidade Federal do Rio Grande do Sul, Porto Alegre, 2005.

10. MASCARENHAS, A. C. Comitê de Bacia Hidrográfica: O Que é, Como Funciona, e que Papel Desempenha na Gestão dos Recursos Hídricos. In: Plenarium, ano III, n.3. Brasília: Câmara dos Deputados, Coordenação de Publicações, 2006.

11. MEIER, M. A. A conjuntura dos instrumentos da política estadual de recursos hídricos do estado do Rio Grande do Sul. 238p. Dissertação (Mestrado). Universidade Federal de Santa Maria, Centro de Ciências Naturais e Exatas, Programa de Pós-Graduação em Geografia e Geociências, RS, 2011.

12. NASCIMENTO, W. M. do; VILLAÇA, M. G. Bacias hidrográficas: planejamento e gerenciamento. Revista Eletrônica da Associação dos Geógrafos Brasileiros - Seção Três Lagoas, MS, № 7, ano 5, 2008. Disponível em:<http://www.cptl.ufms.br/revistageo/Art507_W.Nascimento_M.Vila\%E7 a.pdf> Acesso em 25 abr. 2013.

13. SECRETARIA ESTADUAL DO MEIO AMBIENTE - SEMA. Relatório Anual Sobre a Situação dos Recursos Hídricos no Estado do Rio Grande do Sul Edição 2007/2008. Rio Grande do Sul, 2008.

14. SECRETARIA ESTADUAL DO MEIO AMBIENTE - SEMA. Bacia Hidrográfica do Rio da Várzea, 2010. Disponível em: <http://www.sema.rs.gov.br/>. Acesso em 25 abr. 2013. 